16. Михайлов Д.С. Приготовительный курс зоологии. СПб.: Огризко, 1862. 139 с.

17. Сент-Илер К.К. Элементарный курс зоологии. СПб.: Товарищество «Общественная польза», 1874. $250 \mathrm{c}$.

18. Трайтак Д.И. Александр Яковлевич Герд (18411888) // Биология в школе. 1988. № 6. С. 20-21.

19. Лесгафт П.Ф. Семейное воспитание ребенка и его значение: В 2 т. СПб.: Товарищество художественной печати, 1900.

20. Половцов В.В. Основы общей методики естествознания. М.: Сытин, 1907. 276 с.
21. Игнатьев Б., Соколов С. Наблюдай природу. М.; Петроград: Госиздат, 1923. 96 с.

22. Спенсер Г. Воспитание умственное, нравственное и физическое. СПб.: Губинский, 1906. 230 с.

23. Рибо Т. Опыт исследования творческого воображения: Пер. с фр. СПб.: Пантелеев, 1901. 232 с.

24. Бинэ А., Симон Т. Развитие интеллекта детей. М.: Саблин, 1911. 162 с.

25. Румянцев Е. Как изучалась и изучается душевная жизнь детей? // Душевная жизнь детей. М., 1910. С. 4-65.

26. Севрук Л.С. Методика начального курса естествоведения. СПб., 1902. 428 с.

\title{
THE PROBLEM OF STUDENTS' DEVELOPMENT IN THE THEORY AND PRACTICE OF THE NATIONAL SCHOOL UNTIL 1917 (ON THE EXAMPLE OF NATURAL SCIENCE)
}

(C) 2018

Lamekhova Elena Anatolievna, candidate of pedagogical sciences, associate professor of General Biology and Physiology Department South Ural State Humanitarian Pedagogical University (Chelyabinsk, Russian Federation)

Abstract. The paper deals with the problem of interrelation between education, upbringing and training of students while studying natural sciences, which has always been interesting for teachers and methodologists. This problem is especially urgent now in connection with the further implementation of the GEF of secondary general education, which aims the school to create conditions for students' development and self-realization. The paper considers interpretation of the relationship between teaching, upbringing and development in the educational process in Russian pedagogy in the period up to 1917. It is noted that views on education and upbringing of children in Russia and Europe developed roughly at the same time. Throughout the entire historical period, there was a struggle between supporters of the new education, advocating rapprochement with advanced Russian and Western European science and Russian clergy, preaching church dogma and their opponents, denying any development at all. Long enough unresolved problems were the lack of unified programs for all educational institutions and established terms of training. Principal changes in the system of domestic education are associated with scientific and pedagogical activities of M.V. Lomonosov and his followers. It emphasizes the importance of the idea that appeared in the writings of teachers in the middle of the $19^{\text {th }}$ century. It advised to take into account the age and individual inclinations of children and develop a new methodology based on children's activity and independence, which made it possible to pass to the inductive path of instruction. The process of natural science study from the nineteenth century is regarded as the most effective means of developing the sense organs, logical thinking and observation. It also explains the need to combine inductive and deductive teaching methods and justifies the need to use natural objects, experiments and observations in nature for students' development.

Keywords: training; upbringing; development; federal state educational standard of secondary general education; self-realization; natural science; textbooks; teaching aids; language of science and education; pedagogical problems; didactic problems; methodical problems; inductive deductive teaching methods; biological method.

\section{ПРОВЕРКА И ОЦЕНИВАНИЕ СФОРМИРОВАННОСТИ ПРОФЕССИОНАЛЬНЫХ КОМПЕТЕНЦИЙ: ПРОБЛЕМЫ И ПУТИ ИХ РЕШЕНИЯ (НА МАТЕРИАЛЕ ДИСЦИПЛИНЫ/МОДУЛЯ «МЕТОДИКА ОБУЧЕНИЯ БИОЛОГИИ»)} (C) 2018

Марина Антонина Васильевна, кандидат педагогических наук, доцент кафедры биологии, географии и химии

Арзамасский филиал Национального исследовательского Нижегородского государственного университета им. Н.И. Лобачевского (г. Арзамас, Нижегородская область, Российская Федерачия)

Галкина Елена Александровна, кандидат педагогических наук, доцент кафедры физиологии человека и методики обучения биологии Красноярский государственный педагогический университет им. В.П. Астафьева (2. Красноярск, Российская Федерачия)

Макарова Ольга Борисовна, кандидат педагогических наук, доцент кафедры зоологии и методики обучения биологии

Новосибирский государственный педагогический университет (г. Новосибирск, Российская Федерация)

Аннотащия. В данной статье на примере дисциплины/модуля «Методика обучения биологии» основной профессиональной образовательной программы направления подготовки 44.03.05 Педагогическое образова- 
ние (с двумя профилями подготовки) (уровень бакалавриата) рассматривается один из ключевых вопросов, связанных с формированием профессиональных компетенций будущего бакалавра, - вопрос о процедурах проверки и оценивания профессиональных компетенций. В статье приведен перечень профессиональных компетенций, формируемых средствами дисциплины. Представлен компонентный состав каждой из них. Описаны процедуры и технологии проверки сформированности компонентов профессиональных компетенций - знаний, умений, владений. Приведены примеры заданий каждой из используемых в опыте работы авторов статьи процедур. Установлено, что наименьшие сложности связаны с разработкой заданий, направленных на проверку сформированности деятельностной составляющей компетенций. Раскрыты критерии оценивания деятельности студентов в рамках каждой из обозначенных процедур. Приведены критерии оценивания тестирования, выполнения исследовательских реферативных работ, творческих заданий, мультимедийных презентаций. Показаны сложности, с которыми сталкиваются педагоги при осуществлении данной работы. Основной проблемой определения критериальной базы оценивания итоговых форм контроля является раскрытие преимущественно знаниевой составляющей компетентностного состава дисциплины. Представленные материалы могут быть использованы в опыте деятельности вузовских педагогов, преподающий курс «Методика обучения биологии».

Ключевые слова: федеральный государственный образовательный стандарт; высшее образование; педагогическое образование; бакалавриат; дисциплина; модуль; методика обучения биологии; профессиональные компетенции; компонентный состав компетенций; процедуры и технологии контроля; критерии оценивания; разные виды деятельности студентов; учитель биологии.

Реализация федерального государственного образовательного стандарта высшего образования по направлению подготовки 44.03.05 Педагогическое образование (с двумя профилями подготовки) (уровень бакалавриата) [1] достаточно жестко ставит педагогов перед необходимостью ответственного отношения к процедурам проверки и оценивания образовательных результатов учебной деятельности студентов, выраженных в компетентностной форме.

Несмотря на то, что идеи компетентностного подхода (В.И. Байденко, В.В. Башев, В.А. Болотов, А.В. Брушлинский, С.Г. Воровщиков, Б.С. Гершунский, В.В. Давыдов, Э.Ф. Зеер, И.А. Зимняя, Л.Ф. Иванова, Д.А. Иванов, А.Г. Каспржак, В.В. Краевский, И.Я. Лернер, Е.И. Огарев, Н.Ф. Родионова, А.П. Тряпицына, А.В. Хуторской, Г.П. Щедровицкий, И.Д. Фрумин и др.) являются общепризнанными, их реализация у многих педагогов вызывает серьезные затруднения при разработке контрольных измерительных материалов фонда оценочных средств для проверки сформированности компетенций, формируемых средствами различных дисциплин/модулей.

Анализ литературы по данной проблеме [2-11] позволил установить основные сложности, с которыми сталкиваются педагоги. Среди них - вычленение компонентного состава компетенций, выбор форм контроля его сформированности, определение оптимальных форм проверки сформированности отдельных компонентов, подбор и разработка заданий для различных форм проверки, их соотнесение с конкретными компетенциями, формируемыми дисциплиной; разработка с точки зрения компетентностного состава критериев оценивания различных форм контроля сформированности компетенций и др.

Целью нашей работы стало разрешение выявленных затруднений на примере дисциплины/модуля «Методика обучения биологии», преподавателями которой мы являемся в Арзамасском филиале Нижегородского государственного университета имени Н.И. Лобачевского, Красноярского государственного педагогического университета имени В.П. Астафьева, Новосибирского государственного университета, и представление опыта нашей деятельности.

Учебным планом за дисциплиной закреплен ряд профессиональных компетенций - ПК 1, ПК 2, ПК 4,
ПК 8, ПК 9, ПК 12. Для каждой из них при разработке рабочей программы дисциплины нами были выделены в дефинициях «знать», «уметь», «владеть» характеристики их сформированности. Такая детализация обеспечивает четкую характеристику требований по формированию профессиональных компетенций, на развитие которых направлено изучение каждого из разделов дисциплины, а также впоследствии при организации учебного процесса - вычленение этапов их формирования в процессе контактной работы студентов с преподавателем, содержания самостоятельной работы студентов и формы оценочных средств текущего контроля успеваемости/ промежуточной аттестации (таблица 1).

После завершения данной работы нами были определены процедуры и технологии проверки сформированности компетенций. Для оценивания результатов обучения в виде знаний были выбраны тестирование, индивидуальное собеседование, учебно-исследовательские реферативные работы. Для оценивания результатов обучения в виде умений и владений были выбраны практические контрольные задания на установление последовательности (описать алгоритм выполнения действия), на нахождение ошибок в последовательности (определить правильный вариант последовательности действий), представление мультимедийных презентаций, контрольные задания по теоретическим основам дисциплины.

Следующий этап деятельности заключался в выборе из имеющихся в нашем распоряжении фондов оценочных средств конкретных измерительных материалов, отвечающих задачам проверки компонентного состава компетенций. Их анализ показал, что подавляющее большинство имеющихся материалов малопригодно для использования в учебном процессе в связи с ориентацией на знаниевую компоненту содержания дисциплины. Поэтому были предприняты попытки разработки авторских вариантов заданий контрольных измерительных материалов [12-16]. Сложность при этом заключалась в необходимости «привязки» каждого задания для отдельного компонента конкретной профессиональной компетенции.

Рассмотрим в качестве примеров отдельные задания оценочных средств для образовательных достижений обучающихся, освоивших программу учебной дисциплины «Методика обучения биологии». 
Таблица 1 - Компонентный состав компетенций, формируемых средствами дисциплины/модуля «Методика обучения биологии»

\begin{tabular}{|c|c|}
\hline $\begin{array}{l}\text { Формируемые } \\
\text { компетенции }\end{array}$ & $\begin{array}{c}\text { Планируемые результаты обучения по дисциплине (модулю) } \\
\text { (компонентный состав компетенции) }\end{array}$ \\
\hline $\begin{array}{l}\text { ПК } 1 \\
\text { готовность реа- } \\
\text { лизовывать обра- } \\
\text { зовательные про- } \\
\text { граммы по учеб- } \\
\text { ному предмету в } \\
\text { соответствии с } \\
\text { требованиями } \\
\text { образовательных } \\
\text { стандартов }\end{array}$ & $\begin{array}{l}31 \text { (ПК 1) Знать современные требования, предъявляемые к учебным программам по био- } \\
\text { логии, предусмотренные ГОС школьного биологического образования, ФГОС общего об- } \\
\text { разования с учетом особенностей протекания педагогического процесса как реально } \\
\text { наблюдаемого (в ходе просмотра видеофрагментов), так и модели (в ситуациях, схемах, } \\
\text { таблицах); } \\
\text { У1 (ПК 1) Уметь соотносить учебные программы с поставленными современными норма- } \\
\text { тивными документами задачами образования, воспитания и развития личности обучаю- } \\
\text { щихся при изучении школьного курса биологии, соотносить имеющиеся в них методиче- } \\
\text { ские инструментарии и технологические приемы с поставленными в образовательном } \\
\text { процессе задачами, выбирать учебные программы базовых и элективных курсов по биоло- } \\
\text { гии для основной и средней школы как способы эффективного решения оперативных } \\
\text { учебно-воспитательных задач; } \\
\text { У2 (ПК 1) Уметь характеризовать программы базовых и элективных курсов по биологии } \\
\text { для основной и средней школы, описывать основания выбора учебно-воспитательных за- } \\
\text { дач разных курсов, исходя из требований предметных результатов обучения биологии, } \\
\text { определенных ФГОС общего образования, сформулированных в Фундаментальном ядре } \\
\text { содержания общего образования, примерных программах по биологии для основной и } \\
\text { средней школы; } \\
\text { У3 (ПК 1) Уметь разрабатывать фрагменты учебных программ элективных курсов по } \\
\text { биологии для основной и средней школы, обосновывать организационно-методические } \\
\text { основы их применения с указанием возможностей для решения познавательных и воспи- } \\
\text { тательных задач; } \\
\text { В1 (ПК 1) Моделировать основы авторской программы элективных курсов, конструиро- } \\
\text { вание ее технологических компонентов, комбинирование технологических приемов; } \\
\text { В2 (ПК 1) Владеть эмпирическими и теоретическими методами исследования, примене- } \\
\text { нием их в ходе анализа образовательного процесса с использованием разных вариантов } \\
\text { учебных программ базовых и элективных курсов по биологии для основной и средней } \\
\text { школы как реально протекающего (на примере учебных ситуаций, фрагментов трениро- } \\
\text { вочных уроков и видеозаписей уроков учителей), так и его модели (реальных условий } \\
\text { протекания образовательного процесса) }\end{array}$ \\
\hline $\begin{array}{l}\text { ПК } 2 \\
\text { способность ис- } \\
\text { пользовать со- } \\
\text { временные мето- } \\
\text { ды и технологии } \\
\text { обучения и диа- } \\
\text { гностики }\end{array}$ & $\begin{array}{l}31 \text { (ПК 2) Знать сущность диагностики и мониторинга образовательных достижений обу- } \\
\text { чающихся в образовательном процессе; } \\
32 \text { (ПК 2) Знать современные методики и технологии образовательного процесса; } \\
33 \text { (ПК 2) Иметь представления о ведущих технологиях обучения биологии в основной и } \\
\text { средней школе как средстве реализации ФГОС; } \\
\text { У1 (ПК 2) Уметь описывать качество образовательной деятельности по биологии, условия } \\
\text { его обеспечения в образовательном процессе; характеризовать современные методики и } \\
\text { технологии образовательного процесса, наличие представлений о ведущих технологиях в } \\
\text { образовательном процессе как средстве реализации ФГОС, умение охарактеризовать не- } \\
\text { которые методики диагностики; } \\
\text { У2 (ПК 2) Уметь сравнивать, сопоставлять, анализировать разнообразные технологии, } \\
\text { выделять их структурные компоненты, устанавливать причинно-следственной связь меж- } \\
\text { ду применяемой технологией и ее влиянием на качество образовательного процесса; } \\
\text { В1 (ПК 2) Владеть основами применения инновационных технологий при обучении } \\
\text { школьной биологии в основной и средней школе; } \\
\text { В2 (ПК 2) Проектировать образовательные технологии с целью их применения при диа- } \\
\text { гностировании, мониторинге образовательного процесса; } \\
\text { В3 (ПК 2) Проектировать диагностические процедуры образовательного процесса, вла- } \\
\text { дение методиками диагностики, конструирование протекания образовательного процесса } \\
\text { с прогнозированием возможного образовательного результата }\end{array}$ \\
\hline $\begin{array}{l}\text { ПК } 4 \\
\text { способность ис- } \\
\text { пользовать воз- } \\
\text { можности обра- } \\
\text { зовательной сре- } \\
\text { ды для достиже- } \\
\text { ния личностных, } \\
\text { метапредметных } \\
\text { и предметных } \\
\text { результатов обу- }\end{array}$ & $\begin{array}{l}31 \text { (ПК 4) Знать характеристики образовательной среды как средства достижения лич- } \\
\text { ностных, метапредметных и предметных результатов обучения и условия повышения ка- } \\
\text { чества образовательного процесса по биологии; } \\
32 \text { (ПК 4) Знать виды образовательных результатов изучения биологии - личностные, ме- } \\
\text { тапредметные и предметные; } \\
\text { У1 (ПК 4) Уметь выявлять методологические основы организации образовательной среды } \\
\text { как фактора успешности развития личности, формирования универсальных учебных дей- } \\
\text { ствий; } \\
\text { У2 (ПК 4) Осознавать образовательные результаты школьного курса биологии как ре- } \\
\text { зультат образовательного процесса и средство социализации развиваюейся личности; }\end{array}$ \\
\hline
\end{tabular}


Марина А.В., Галкина Е.А., Макарова О.Б.

чения и обеспечения качества видами заданий и технологий, методами и формами работы, используемыми при изучении учебновоспитательного процесса средствами преподаваемых учебных предметов школьного курса биологии основной и средней школы;

В1 (ПК 4) Использовать деятельностный и компетентностный подходы к формированию образовательных результатов учебной деятельности по курсу школьной биологии основной и средней школы;

В2 (ПК 4) Владеть способностью к оценочным суждениям о качественном уровне образовательного процесса на основе сформированности образовательных результатов школьного курса биологии основной и средней школы

\section{ПK 8}

способность проектировать образовательные программы

31 (ПК 8) Знать современные требования, предъявляемые к образовательным программам с учетом особенностей протекания педагогического процесса как реально наблюдаемого (в ходе просмотра видеофрагментов), так и модели (в ситуациях, схемах, таблицах);

У1 (ПК 8) Уметь соотносить образовательные программы с поставленными современными нормативными документами задачами образования, воспитания и развития личности обучающихся, соотносить имеющиеся в них методические инструментарии и технологические приемы с поставленными в образовательном процессе задачами;

У2 (ПК 8) Уметь характеризовать действующие образовательные программы, описывать основания выбора учебно-воспитательных задач разных, исходя из требований предметных результатов обучения биологии, определенных ФГОС общего образования, сформулированных в Фундаментальном ядре содержания общего образования, примерных программах по биологии для основной и средней школы;

В1 (ПК 8) Проектировать основы образовательных программ, конструировать ее технологические компоненты, комбинировать технологические приемы;

В2 (ПК 8) Владеть эмпирическими и теоретическими методами исследования, применением их в ходе анализа образовательного процесса с использованием разных вариантов образовательных программ как реально протекающего (на примере учебных ситуаций, фрагментов тренировочных уроков и видеозаписей уроков учителей), так и его модели (реальных условий протекания образовательного процесса)

ПК 9

способность проектировать индивидуальные образовательные маршруты обучающихся
31 (ПК 9) Знать требования к разработке индивидуальных образовательных маршрутов; 32 (ПК 9) Знать образовательные результаты изучения биологии в общеобразовательной школе;

33 (ПК 9) Знать модели, методики, технологии и приемы обучения, применяемые при обучении биологии в общеобразовательной школе;

У1 (ПК 9) Уметь проектировать индивидуальные образовательные маршруты обучающихся;

У2 (ПК 9) Уметь реализовывать индивидуальные образовательные маршруты обучающихся;

В1 (ПК 9) Владеть системой практических умений и навыков, обеспечивающих достижение образовательных результатов изучения биологии в общеобразовательной школе при использовании индивидуальных образовательных маршрутов обучающихся;

В2 (ПК 9) Владеть умениями анализа эффективности использования индивидуальных образовательных маршрутов обучающихся

\section{ПК 12}

способность руководить учебноисследовательской деятельностью обучающихся

\section{1 (ПК 12) Знать основы организации исследовательской деятельности учащихся;}

У1 (ПК 12) Уметь отбирать тематику исследовательской деятельности учащихся;

У2 (ПК 12) Уметь организовывать учащихся на выполнение разных видов исследовательской деятельности;

В1 (ПК 12) Владеть методологией организации научного исследования;

В2 (ПК 12) Владеть методикой организации исследовательской деятельности учащихся
Тестовые задания:

1. Учебные программы по биологии для основной школы по ФГОС имеют структуру:

а) линейную;

б) ступенчатую;

в) концентрическую;

г) сферическую (ПК 1).

2. ФГОС общего образования в качестве важнейшей технологии достижения образовательных результатов изучения школьного курса биологии рассматривает: а) технологию проектной деятельности;

б) ИКТ технологии;

в) технологию модульного обучения;

г) технологию развития критического мышления (ПК 2).

3. K образовательным результатам изучения школьного курса биологии не относятся:

а) личностные;

б) предметные;

в) внутрипредметные;

г) метапредметные (ПК 4). 
Марина А.В., Галкина Е.А., Макарова О.Б.

4. Участие учителя биологии в разработке образовательной программы образовательного учреждения заключается в:

а) разработке рабочей учебной программы по предмету;

б) разработке программы внеурочной работы;

в) разработке отдельных заданий для проверки предметных результатов;

г) разработке тематики проектной деятельности по предмету (ПК 8).

5. Действующий государственный стандарт икольного биологического образования должен соответствовать следующим требованиям:

а) должен быть ориентирован на нормирование учебной нагрузки школьника;

б) должен быть ориентирован на нормирование учебной нагрузки учителя;

в) должен обеспечивать преемственность ступеней обучения;

г) содержание и структура стандарта должны быть функционально полными с точки зрения развития личности (ПК 9).

6. Способность икольного учителя биологии руководить учебно-исследовательской деятельностью учащихся прописана в следующих нормативных документах:

а) Закон об образовании в РФ;

б) ФГОС общего образования;

в) рабочая учебная программа по предмету;

г) Профессиональный стандарт педагога (ПК 12).

Примерная тематика

учебно-исследовательских реферативных

работ, мультимедийных презентаций

1. Особенности формирования универсальных учебных действий познавательной направленности.

2. Особенности оценки личностных результатов изучения курса биологии основной школы.

3. Особенности УМК курса «Введение в биологию» 5 класса по линейному варианту программы Н.И. Сонина.

4. Метапредметные результаты изучения школьного курса биологии 6 класса по программе Н.И. Романовой «Вектор».

5. Плюсы и минусы вариативности УМК по биологии для основной школы.

6. Сложности, стоящие перед учителем биологии при выборе УМК для основной школы.

7. Сложности в работе учителя биологии при разработке ООП школы.

8. Сложности в работе учителя биологии при разработке оценочных средств предметных результатов изучения биологии основной школы.

9. Образовательные технологии, используемые при изучении школьного курса биологии 10-11 классов.

10. Технология проектной деятельности как технологии формирования метапредметных результатов изучения школьного курса биологии основной общеобразовательной школы.

\section{Контрольные задания}

по теоретическим основам дисциплинь

1. Назовите и охарактеризуйте новую цель образования в Российской Федерации, определенную
Федеральными государственными образовательными стандартами основной школы.

2. Перечислите последовательность разделов школьного курса биологии, изучаемых в основной школе.

3. Охарактеризуйте структуру Фундаментального ядра содержания общего образования.

4. Дайте определение универсальным учебным действиям.

5. Раскройте классификацию универсальных учебных действий школьного курса биологии основной школы.

6. Перечислите группы образовательных результатов изучения курса биологии основной школы.

7. В чем заключаются особенности проектной деятельности учащихся по биологии?

8. С какими сложностями может столкнуться школьный учитель биологии при организации индивидуальной проектной деятельности учащихся?

9. Какие технологии могут быть использованы при формировании универсальных учебных действий познавательной направленности?

10. Какие технологии могут быть использованы при формировании метапредметных результатов изучения биологии в основной школе?

С определенными сложностями мы столкнулись при разработке критериального аппарата оценивания результатов промежуточной аттестации. Ведь существовавшие ранее критерии оценивания результатов зачета или экзамена характеризовали, как правило, знания и умения содержательного характера дисциплины, но не отражали сформированность компетенций. Поэтому пришлось пересмотреть существующие критерии с позиций решаемой проблемы.

В ходе промежуточной аттестации по дисциплине осуществляется оценка сформированности компонентов компетенций (полнота знаний/ наличие умений/ навыков), т.е. результатов обучения, указанных в таблице, на основе оценки усвоения содержания дисциплины.

Обобщенная оценка сформированности компонентного состава компетенции в ходе промежуточной аттестации по дисциплине проводится на основе учета текущей успеваемости в ходе освоения дисциплины и учета результатов сдачи зачета, защиты курсовой работы, сдачи экзамена.

Выявленные признаки несформированности компонентов хотя бы одной компетенции не позволяют выставить интегрированную положительную оценку сформированности компетенций и освоения дисциплины на данном этапе обучения.

Так, обобщенная оценка сформированности компонентного состава компетенций на защите курсовой работы осуществляется по оценочной шкале «отлично», «хорошо», «удовлетворительно», «неудовлетворительно»:

- «отлично» - сформированность компонентного состава компетенций соответствует требованиям компетентностной модели будущего выпускника на данном этапе обучения, основанным на требованиях ФГОС ВО по направлению подготовки, в выполненной курсовой работе полностью раскрыты все вопросы теоретической и практической части; материал изложен четко, логично, грамотно; соблюдены все 
требования, предъявляемые к оформлению; студент при публичной защите обнаружил свободное владение научной проблемой, освещенной в работе;

- «хорошо» - сформированность компонентного состава компетенций соответствует требованиям компетентностной модели будущего выпускника на данном этапе обучения, основанным на требованиях ФГОС ВО по направлению подготовки, в выполненной курсовой работе неполно освещен какой-либо вопрос теоретической и практической части; имеются недочеты в оформлении; студент при публичной защите обнаружил достаточное владение научной проблемой, освещенной в работе;

- «удовлетворительно» - сформированность компонентного состава компетенций соответствует в целом требованиям компетентностной модели будущего выпускника на данном этапе обучения, основанным на требованиях ФГОС ВО по направлению подготовки, в выполненной курсовой работе не отражены результаты самостоятельной исследовательской работы; отсутствует четкость и грамотность в изложении материала; не учтены требования, предъявляемые к структуре работы; имеются серьезные ошибки по предмету и в оформлении; студент при публичной защите обнаружил слабое владение научной проблемой, освещенной в работе;

- «неудовлетворительно» - сформированность компонентного состава компетенций не соответствует требованиям компетентностной модели будущего выпускника на данном этапе обучения, основанным на требованиях ФГОС ВО по направлению подготовки, в выполненной курсовой работе допущены серьезные ошибки в теоретической или практической части работы; отсутствует самостоятельная работа; отсутствует четкость в изложении материала; не учтены требования, предъявляемые к структуре работы; содержание работы не соответствует структуре; имеются серьезные ошибки в оформлении; студент при публичной защите обнаружил крайне слабое владение научной проблемой, освещенной в работе.

Обобщенная оценка сформированности компонентного состава компетенций на экзамене осуществляется по оценочной шкале «отлично», «хорошо», «удовлетворительно», «неудовлетворительно»:

- «отлично» - сформированность компонентного состава компетенций соответствует требованиям компетентностной модели будущего выпускника на данном этапе обучения, основанным на требованиях ФГОС ВО по направлению подготовки, студент готов самостоятельно решать стандартные и нестандартные профессиональные задачи в предметной области дисциплины в соответствии с видами профессиональной деятельности осваиваемой образовательной программы;

- «хорошо» - сформированность компонентного состава компетенций соответствует требованиям компетентностной модели будущего выпускника на данном этапе обучения, основанным на требованиях ФГОС ВО по направлению подготовки, но студент готов самостоятельно решать только различные стандартные профессиональные задачи в предметной области дисциплины в соответствии с видами профессиональной деятельности осваиваемой образовательной программы;

- «удовлетворительно» - сформированность компонентного состава компетенций соответствует в целом требованиям компетентностной модели будущего выпускника на данном этапе обучения, основанным на требованиях ФГОС ВО по направлению подготовки, но студент способен решать лишь минимум стандартных профессиональных задач в предметной области дисциплины в соответствии с видами профессиональной деятельности осваиваемой образовательной программы;

- «неудовлетворительно» - сформированность компонентного состава компетенций не соответствует требованиям компетентностной модели будущего выпускника на данном этапе обучения, основанным на требованиях ФГОС ВО по направлению подготовки, студент не готов решать профессиональные задачи в предметной области дисциплины в соответствии с видами профессиональной деятельности осваиваемой образовательной программы.

Одновременно с этим отрабатывались критерии оценивания различных видов деятельности студентов с учетом выбранных нами процедур и технологий проверки сформированности компетнций. Так, критерии оценивания контрольных заданий по теоретическим основам дисциплины выглядят следующим образом:

- «отлично» выставляется, когда студент глубоко и прочно усвоил материал, исчерпывающе, последовательно, грамотно и логически стройно его излагает, свободно справляется с ситуационными заданиями, правильно обосновывает принятые решения, умеет самостоятельно обобщать и излагать материал, не допуская ошибок;

- «хорошо» выставляется, если студент твердо знает материал, грамотно и по существу излагает его, не допускает существенных неточностей в ответе на вопрос, может правильно применять теоретические положения и владеет необходимыми умениями и навыками при выполнении аналитических заданий;

- «удовлетворительно» выставляется в том случае, когда студент освоил только основной материал, но не знает отдельных деталей, допускает неточности, недостаточно правильные формулировки, нарушает последовательность в изложении материала и испытывает затруднения в выполнении практических заданий;

- «неудовлетворительно» выставляется студенту, ответ которого содержит существенные пробелы в знании основного содержания учебного материала, не умеет использовать полученные знания при решении практических задач.

Реализация всех вышерассмотренных действий обеспечила накопление контрольных измерительных материалов для формирования фонда оценочных средств, разработки рабочей учебной программы по дисциплине, переработки вопросов и заданий к зачетам и экзаменам. Считаем, что наш опыт может быть востребован педагогами других вузов и будет способствовать формированию профессиональных компетенций бакалавров. 
В заключение следует отметить, что подготовка бакалавров педагогического образования к реализации профессиональной деятельности в качестве школьного учителя остается актуальной проблемой высшего педагогического образования. Она по-прежнему требует глубокого теоретического обоснования, поиска новых путей и способов решения.

\section{Список литературы:}

1. Федеральный государственный образовательный стандарт высшего образования. Уровень высшего образования. Бакалавриат. Направление подготовки 44.03.05 Педагогическое образование (с двумя профилями подготовки). Утвержден приказом Министерства образования и науки Российской Федерации от 09.02.2016 г. № 91 [Электронный ресурс] // Министерство образования и науки Российской Федерации. - http://минобрнауки.рф/документы/8073.

2. Аглямова 3.Ш., Камашева Ю.Л. Реализация компетентностного подхода при разработке учебнометодического обеспечения // Образование: традиции и инновации: материалы III междунар. науч.практ. конф. (21 октября 2013 года) / отв. ред. Н.В. Уварина. Прага: World press s г.о., 2013. С. 6-10.

3. Галкина Е.А., Марина А.В., Макарова О.Б. Новые подходы в методической подготовке студентовбиологов к работе в условиях перехода на ФГОС основного общего образования // Вестник КГПУ им. В.П. Астафьева. 2015. № 3 (33). С. 48-52.

4. Галкина Е.А., Марина А.В., Макарова О.Б. Актуализация учебных программ ВПО в соответствии с требованиями профессионального стандарта педагога // Вестник НГПУ. 2015. № 3. С. 22-33.

5. Ефремова Н.Ф. Формирование и оценивание компетенций в образовании: монография. Ростов-наДону: Аркол, 2010. 386 с.

6. Камашева Ю.ЈI. Оценка качества учебнометодического обеспечения основных образовательных программ высшего профессионального образования: дис. ... канд. пед. наук. Казань, 2009. 242 с.

7. Лазаренко И.Р. Региональный контекст проектирования и реализации основных профессиональных образовательных программ в педагогическом вузе // Вестник Новосибирского государственного педагогического университета. 2015. № 6. С. 7-14.

8. Тюнникова Ю.С. Концептуализация системы подготовки будущих педагогов к инновационной деятельности // European Journal of Contemporary Education. 2015. Vol. 11, № 1. C. 98-112.

9. Харитонова О.В. Обновление образовательных программ высшего профессионального образования для обеспечения непрерывного процесса подготовки кадров // Universum: Вестник Герценовского университета. 2011. № 2. С. 17-20.

10. Харитонова С.С., Марина А.В. Использование модульно-рейтинговой системы оценивания образовательных результатов производственной практики студентов-бакалавров педагогического образования // Педагогика высшей школы. 2016. № 3. С. 47-53.

11. Харитонова С.С., Марина А.В., Опарина С.А. Использование модульно-рейтинговой системы оценивания результатов обучения бакалавров педагогического образования (на материале курса «Методика обучения биологии») // Педагогика высшей школы. 2017. № 2 (08). С. 46-50.

12. Марина А.В., Шеманаев В.А. Практика в системе профессионального образования и личностного роста студента-бакалавра. Выпуск VII: учебнометодическое пособие / под общ. ред. А.В. Мариной. Арзамасский филиал ННГУ. Арзамас: Арзамасский филиал ННГУ, 2017. 213 с.

13. Марина А.В. Практикум по методике обучения биологии. Часть I. Арзамас: Арзамасский филиал ННГУ, 2017. 102 с.

14. Методологические проблемы современного школьного биологического образования: монография / Н.3. Смирнова, Е.Н. Прохорчук, Т.В. Голикова, И.А. Зорков, Е.А. Галкина. Красноярск: КГПУ им. В.П. Астафева. 2015. 322 с.

15. Учебные занятия в условиях реализации ФГОС: учебное пособие / Н.3 Смирнова, Н.М. Горленко, Е.А. Галкина, И.А. Зорков. Красноярск: КГПУ им. В.П. Астафева. 2015. 190 с.

16. Макарова О.Б., Никитина Л.Я., Сивохина Л.Н. Практикум по методике обучения биологии: учебнометодическое пособие. Новосибирск: Изд-во НГПУ, 2008. 92 c.

\title{
VERIFICATION AND EVALUATION OF PROFESSIONAL COMPETENCE DEVELOPMENT: PROBLEMS AND WAYS OF THEIR SOLVING (ON THE MATERIAL OF THE DISCIPLINE/MODULE «METHODS OF TEACHING BIOLOGY»)
} (C) 2018

\author{
Marina Antonina Vasilyevna, candidate of pedagogical sciences, \\ associate professor of Biology, Geography and Chemistry Department \\ Arzamas branch of National Research Lobachevsky State University of Nizhny Novgorod \\ (Arzamas, Nizhny Novgorod Region, Russian Federation) \\ Galkina Elena Alexandrovna, candidate of pedagogical sciences, \\ associate professor of Human Physiology and Methods of Biology Teaching Department \\ Krasnoyarsk State Pedagogical University named after V.P. Astafiev (Krasnoyarsk, Russian Federation) \\ Makarova Olga Borisovna, candidate of pedagogical sciences, \\ associate professor of Zoology and Methods of Biology Teaching Department \\ Novosibirsk State Pedagogical University (Novosibirsk, Russian Federation)
}

Abstract. The following paper considers one of the key issues related to prospective bachelor's professional competencies development on the example of «Methods of Biology Teaching». The paper presents a list of professional competencies developed by means of the discipline. The component composition of each of them is presented. The paper describes development procedures and technologies of professional competences components check knowledge, abilities and possession. The author gives examples of each task. It is established that the least difficul- 
ties are associated with verifying competencies activity component development. The authors reveal criteria of students' activity estimation within each of the designated procedures. The authors give criteria for the evaluation testing, exploratory abstract works, creative jobs, and multimedia presentations. The difficulties faced by teachers in the implementation of this work are shown. The main problem of the final forms control criterion evaluation is the disclosure of main knowledge component of the competence of the discipline. The presented materials can be used by university teachers, teaching the course «Methods of Biology Teaching».

Keywords: federal state educational standard; higher education; pedagogical education; bachelor degree; discipline; module; methodology of biology teaching; professional competences; component composition of competences; control procedures and technologies; evaluation criteria; different types of students' activities; teacher of biology.

УДК 378.147 .227

Статья поступила в редакцию 20.10.2017

\section{ИНТЕГРАТИВНО-МОДУЛЬНАЯ ТЕХНОЛОГИЯ ОБУЧЕНИЯ ОБЩЕЙ ХИМИИ}

(C) 2018

Передерина Ирина Александровна, кандидат химических наук, доцент кафедры химии

Тверякова Елена Никитична, кандидат химических наук, доцент кафедры химии Сибирский государственный медицинский университет (2. Томск, Российская Федерация)

Мирошниченко Юлия Юрьевна, кандидат химических наук, доцент кафедры общей химии и химической технологии

Национальный исследовательский Томский политехнический университет (г. Томск, Российская Федерациия)

Дрыгунова Лариса Александровна, кандидат химических наук, доцент кафедры химии

Зыкова Мария Владимировна, кандидат фармацевтических наук, доцент, заведующий кафедрой химии

Жолобова Галина Александровна, кандидат химических наук, доцент кафедры химии

Голубина Ольга Александровна, кандидат химических наук, доцент кафедры химии

Сибирский государственный медицинский университет (2. Томск, Российская Федерация)

Аннотация. Авторами показана возможность применения инновационных образовательных технологий в учебном процессе классического медицинского вуза. Кроме традиционных методов обучения и контроля (анкетирование, контрольные работы, коллоквиумы, зачеты и экзамены) на кафедре химии Сибирского государственного медицинского университета (СибГМУ) внедрена интегративно-модульная технология (ИМТ) обучения студентов-медиков общей химии. При планировании образовательных программ в рамках компетентностного подхода произведена замена парадигмы обучения на парадигму продуктивного учения при большей самостоятельности студентов, которые проектируют собственные профессиональные и универсальные компетенции.

В содержательном блоке дисциплины «Химия» выделены два компонента: инвариантный и вариативный. Вариативный компонент - элективный курс, посвященный химии биологически активных и токсичных соединений. В статье авторы излагают результаты сочетания академических и инновационных методов и технологий обучения. Кроме того, предложен примерный алгоритм усвоения материала на примере модуля курca, посвященного адсорбционным равновесиям и процессам. Он содержит теоретическую подготовку, обеспеченную учебниками, лекционным текстом и методическими пособиями. Качественную оценку учебной работы студенты проводят самостоятельно с помощью тестовых заданий и в ходе выполнения практического задания на лабораторных занятиях. Описанная в работе модель интегративно-модульного обучения химии позволяет значительно повысить мотивацию студентов в процессе обучения, улучшить формирование профессиональных компетенций путем оптимизации аудиторной и самостоятельной работы студента.

Ключевые слова: интегративно-модульная технология; элективный курс химии; инвариантный и вариативный компоненты обучения; медицинский профиль; адсорбционные равновесия и процессы; технологии обучения; методика обучения; инновационные методы обучения; профессиональные компетенции; компетентностный поход.

Химия - фундаментальная наука. Поэтому независимо от выбранной профессиональной специализации студенты должны усваивать законы и методы этой науки. Высокие требования к современному специалисту остро ставят вопрос перед преподавателями высшей школы о совершенствовании методов обучения, преемственности и координации изучаемых дисциплин. Это отмечали еще выдающиеся педагоги прошлого; например, Я.А. Коменский в XVII веке писал: «Всё, что находится во взаимной связи, должно преподаваться в такой же связи» [1]. Основные принципы «Великой дидактики» Я.А. Коменского являются актуальными и на сегодняшний день.

Химические дисциплины тесно связаны с биохимией, нормальной и патологической физиологией, гигиеной. Цели, стоящие перед современным меди- цинским вузом, определяются необходимостью внедрения компетентностного подхода в подготовке студентов, с применением элементов ИМТ обучения $[2 ; 3]$, основанной на личностно-ориентированной концепции образования.

Поэтому на кафедре химии СибГМУ внедрили концепцию интегративно-модульного развивающего обучения студентов-медиков 1 курса по программе дисциплины «Химия» в рамках изучения вопросов общей, неорганической, физической и коллоидной химии в первом семестре.

Традиционные подходы [4-6] в современном образовании не всегда эффективны. Увеличение количества информации [7] предполагает быструю ее передачу для эффективного усвоения знаний. 